\title{
Attitudes toward genomics and precision medicine
}

www.cambridge.org/cts

\section{Implementation, Policy and Community Engagement Research Article}

Cite this article: DuBois JM, Mozersky J, Antes A, English T, Parsons MV, and Baldwin K. Attitudes toward genomics and precision medicine. Journal of Clinical and Translational Science 5: e120, 1-9. doi: 10.1017/cts.2021.774

Received: 18 November 2020

Revised: 17 March 2021

Accepted: 23 March 2021

\section{Keywords:}

Bioethics; ELSI; precision medicine; attitudes; measurement

\section{Address for correspondence:}

J.M. DuBois, DSc, PhD, Division of General Medical Sciences, Washington University School of Medicine, 4523 Clayton Ave. Campus Box 8005, St. Louis, MO 63110, USA.

Email: duboisjm@wustl.edu

\author{
James M. DuBois ${ }^{1}(\mathbb{1})$, Jessica Mozersky ${ }^{1}$ (i) , Alison Antes $^{1}$ (i), Tammy English², \\ Meredith V. Parsons ${ }^{1}\left(\mathbb{C}\right.$ and Kari Baldwin ${ }^{1}$
}

${ }^{1}$ Division of General Medical Sciences, Washington University School of Medicine, St. Louis, MO, USA and ${ }^{2}$ Department of Psychological \& Brain Sciences, Washington University in St. Louis, St. Louis, MO, USA

\section{Abstract}

Purpose: This paper reports on a novel measure, attitudes toward genomics and precision medicine (AGPM), which evaluates attitudes toward activities such as genetic testing, collecting information on lifestyle, and genome editing - activities necessary to achieve the goals of precision medicine. Discussion: The AGPM will be useful for researchers who want to explore attitudes toward genomics and precision medicine. The association of concerns about precision medicine activities with demographic variables such as religion and politics, as well as higher levels of education, suggests that further education on genomic and precision activities alone is unlikely to shift AGPM scores significantly. Methods: We wrote items to represent psychological and health benefits of precision medicine activities, and concerns about privacy, social justice, harm to embryos, and interfering with nature. We validated the measure through factor analysis of its structure, and testing associations with trust in the health information system and demographic variables such as age, sex, education, and religion. Results: The AGPM had excellent alpha reliability (.92) and demonstrated good convergent validity with existing measures. Variables most strongly associated with higher levels of concern with precision medicine activities included: regular religious practice, republican political leanings, and higher levels of education.

\section{Introduction}

Precision medicine has been defined as "an approach to disease treatment and prevention that seeks to maximize effectiveness by taking into account individual variability in genes, environment, and lifestyle" [1, p. 6]. It has been touted as having the potential to generate "more accurate diagnoses, more rational disease prevention strategies, better treatment selection, and the development of novel therapies" [1, p. 6]. Genomics contributes not only to precision medicine - tailored treatment and disease prevention for individuals - but also to public health through population-based pre-natal, neonatal, and adult screening and testing.

Achieving the goals of precision medicine and public health genomics will require patient engagement with diverse health-related activities that include more than genomics - activities such as consenting to the collection of health behavior and environmental data, permitting data storage and sharing, acting upon tailored recommendations, and supporting new technologies (e.g., CRISPR and stem cell therapies). Without engagement by patients, the promise of precision medicine cannot be realized [2]. Accordingly, the National Institutes of Health's (NIH) All of Us precision medicine initiative seeks to "transform patients into partners" who will "help to raise and answer research questions" [3, p. 746].

Attitudes and value commitments can significantly impact health behaviors [4,5]. For example, negative attitudes, religious beliefs, and lack of trust negatively impact compliance, timely referrals, information sharing with providers, and participation in genetic testing [6-8]. Accordingly, engagement with the diverse activities surrounding precision medicine and public health genomics will be affected by attitudes and values.

Understanding and addressing the public's attitudes and values will therefore be key to precision medicine and public health genomics. A failure to address attitudes and values risks exacerbating current health disparities if only certain members of the population choose to engage with precision medicine activities. For example, evidence suggests that Blacks are less likely to undergo genetic testing for BRCA mutations because of beliefs that genetic testing will increase stigma, possibly exacerbating breast cancer disparities [8].

Currently, no instruments exist to measure attitudes toward the broad array of activities associated with genomics and precision medicine. Measures exist that assess attitudes toward select elements of precision medicine such as genetic testing [9-12], genetic counseling [4], or trust in health information systems [13]. But none examine the full array of activities included within precision medicine. A large survey polled opinions about the precision medicine initiative [14], 
but it did not generate a measure that would identify the latent factors (such as privacy or social justice concerns) that might explain attitudes toward the activities.

Our project aimed to develop and validate a new measure of attitudes toward genomics and precision medicine (AGPM) with the following requirements:

1. Addresses a wide array of activities associated with precision medicine

2. Provides an overall score indicating levels of concern with genomic and precision medicine activities

3. Assesses the latent factors that explain overall attitudes toward these activities

4. Written at an 8 th grade level

5. Incorporates educational videos so that the attitudes assessed are informed by basic information about the activities

Such a measure will be useful in studies that aim to understand factors associated with attitudes toward precision medicine, or that wish to increase engagement with precision medicine activities by addressing participant's values and concerns. Additionally, this project aimed to gather preliminary data on the demographic and individual characteristics that predict attitudes toward a broad array of genomic and precision medicine activities.

\section{Materials and Methods}

Our project proceeded in several stages: Item writing; cognitive interviews and item revision; study $1(n=532)$ with an initial 53-item version of the AGPM for an exploratory factor analysis; and study $2(n=517)$ with a revised 38 -item version of the AGPM for confirmatory factor analysis. We assessed convergent and divergent validity of the final AGPM by examining associations of AGPM scores with existing validated measures of related attitudes. Finally, we explored how demographic variables were associated with attitudes toward genomics and precision medicine.

\section{Item Writing}

While genomics is critical to precision medicine, precision medicine includes additional diverse activities such as microbiomics, passive data collection through wearable devices, environmental data collection, analysis of electronic health records, and broad data sharing. We identified core activities through both a literature review and cognitive interviews with a medical geneticist and genetic counselor who work in the precision medicine core of an NIH CTSA-funded institute [2,3,15-18]. The AGPM explores attitudes toward six domains of activities: (a) post-natal genetic testing, (b) collecting information on lifestyle, bacteria, and environmental toxins, (c) storing and sharing samples and data, (d) genome editing, (e) stem cell therapy and research, and (f) prenatal genetic testing.

Because the AGPM assesses attitudes toward complex, technical activities that often have unfamiliar terms such as "microbiome" or equivocal terms such as "gene editing," each activity is described in lay terms using a brief video with audio, graphics and text. Participants view this information prior to indicating their agreement or disagreement with statements that describe benefits and concerns associated with the activities. Items have a Flesch-Kincaid reading level of 8.5; writing accurate items below an 8 th grade level is generally not feasible due to the complexity of the topics addressed. The videos are designed to aid comprehension of complex material. Participants indicate their agreement with each item using a 7-point Likert scale ranging from strongly disagree to strongly agree.

Consistent with earlier work by Morren et al. [9], we expected that the measure's latent factors would derive from underlying value commitments that could be expressed in terms of perceived benefits from activities (e.g., improving health) and concerns with activities (e.g., violating privacy) - rather than the activities themselves (e.g., broadly sharing data). Accordingly, we wrote at least nine items to represent each of the following five expected benefit or concern factors: (1) nonhealth benefits, (2) health benefits, (3) concerns about nature and human life, (4) concerns about social justice, and (5) concerns about privacy and personal discrimination. These factors were derived from the ELSI literature [2,3,19-24] and existing measures of attitudes toward specific activities such as genetic testing [9,11,12,23-27], prenatal testing [25-27,29], genetic counseling [14], or data gathering, storage and use $[15,31,32]$. While we wrote every item to address one of these five factors, we tailored the items to fit the specific precision medicine activity. For each factor, we wrote items that were both positive and negative in valence, to increase variance in responses and reduce socially desirable responding.

\section{Cognitive Interviews and Item Revision}

Following best-practice recommendations for scale development [28], initial scale items were subjected to expert review and then cognitive interviewing [29]. A medical geneticist and a genetic counselor reviewed the measure to ensure vignettes were accurate and that related items did not ignore important issues. We then conducted cognitive interviews with five individuals who were diverse in terms of race, religion, socioeconomic status, age, and gender. Items and scales were revised based on expert review and cognitive interviews prior to initiating the preliminary validation study. Following revisions, we retained 53 of the original 57 items.

\section{Study 1}

A 53-item version of the AGPM was uploaded into Qualtrics survey software. Participants $(n=532)$ were recruited through Mechanical Turk (MTurk), which matches "workers" to survey researchers. A recent study found that MTurk workers provide nationally representative samples that are superior to the nationally stratified sample of the Cooperative Congressional Election Survey (CCES) [30], and it has been used previously in ELSI research [13]. MTurk workers were paid $\$ 2$ to complete the survey. To maximize the quality of responses, we added 3 attention check items (e.g., "If you are paying attention, select strongly agree"). Participants needed to answer all three correctly for their data to be retained.

Exploratory factor analysis (EFA) with promax rotation was used to assess the factor structure of the AGPM scale and identify poorly performing items (e.g., high cross-loadings or low factor loading across all factors) so that we could refine the measure and reduce its length.

\section{Study 2}

Study 2 used the same approach as study 1 for survey delivery and recruitment. We administered the 40 -item version of the AGPM to a second sample of MTurk participants $(n=517)$. We ran another EFA (with promax rotation) on a random sample of 200 of these participants and found the same five-factor solution. Two items 
were discarded due to low primary factor loading $(<.40)$; another item was trimmed because it was redundant with other items and cutting it did not reduce scale reliability. We then ran a Confirmatory Factor Analysis (CFA) with maximum likelihood (ML) estimation in the remaining sample of 317 to confirm the factor structure.

\section{Construct Validation Approach}

We tested the convergent validity of the AGPM by examining the association of the five factors, and an overall AGPM score, with previously validated measures.

1. The Attitudes toward Genetic Testing (AGT) measure. The AGT consists of 13 items: 6 items are favorable statements about DNA testing, and 7 items express reservations or concerns; these scales have acceptable reliability ( $\alpha=.80$ and 0.63 , respectively) [9].

2. The System Trust Index (STI). The STI consists of 20 items. It measures of levels of trust in the healthcare information system, and generates four subscale scores: competency, fidelity, integrity, and trustworthiness. In a validation study with 1011 participants, the STI demonstrated excellent reliability $(\alpha=.84)$ and construct validity [13].

3. 10-Item Personality Inventory (TIPI). The TIPI is a 10 -item test that measures the big five personality traits: extraversion, agreeableness, conscientiousness, emotional stability, and openness to experience, with excellent test-retest reliability $(r=.72)$ and construct validity [31].

The AGT and STI measures examine four of the six activities examined in the AGPM, and they tap into the underlying factors under examination such as benefits and privacy and social justice concerns. Thus, we expected moderate to large correlations of the new AGPM scales with the AGT and STI, which would provide evidence of construct validity. We expected the AGPM's benefit scale to be associated with the TIPI conscientiousness scores because prior work has demonstrated that individuals higher in conscientiousness are in better health and engage in more health-promoting behaviors [32].

\section{Exploration of Demographic Variables}

Based on prior literature, we expected that racial minorities [8], rural participants [4], republican-leaning individuals [33], and people who reported higher levels of religiosity [34] would have higher levels of concern as indicated by overall AGPM scores. Items assessing religiosity - whether individuals identify with a religious affiliation and how often they attend church or a place of worship - and political orientation were adapted from Gallup polls [35]. We created a new item ("How important would you say spirituality is in your own life?") to explore spirituality, which we thought might perform differently from items exploring formal religious commitments. We additionally gathered standard demographic data on income, education, employment status, race, sex, and age. Location of residence was assessed by asking which category - Urban, Suburban, Large Town, and Small Town or Rural best describes where the participant currently lives. We provided participants definitions of these categories based on population size and proximity to an urban core. Participants also rated their general level of health over the past 4 weeks.

\section{Ethics Statement}

This study was reviewed by the Washington University in St. Louis Institutional Review Board. It was approved as an exempt study. Participants were provided with an information sheet and were asked to click on the survey link if they agreed to participate.

\section{Results}

\section{Descriptive Data}

Complete aggregated demographic data for Studies 1 and 2 are provided in Table 1 . The sample was $52 \%$ male; $74 \%$ were $20-39$ years old; $80 \%$ were White, $13 \%$ Black, $6 \%$ Asian, $3 \%$ American Indian or Alaskan Native, and $11 \%$ identified their ethnicity as Hispanic. Sixtytwo percent were employed full-time; the mode for income was \$4575,000 (33\%) with $24 \%$ earning more and $41 \%$ less. Seventy percent lived in urban or suburban areas. Political and religious preferences were measured only in study 2. 59\% identified as Democrat or Democrat-leaning. $41 \%$ had no religious affiliation, while $51 \%$ identified as Protestant, Christian, or Catholic, and $9 \%$ reported affiliation with another religion. $73 \%$ reported practicing their religion seldom or never. $36 \%$ stated that spirituality was important or very important to them. The sample was overwhelmingly healthy, with $82 \%$ reporting good, very good, or excellent health.

Table 2 presents ranges, mean scores, and standard deviations for the AGPM (total score and five subscales), STI (four scales), AGT (two scales), TIPI (five subscales), and questions about religion, spirituality, and general health. The AGPM scales demonstrated good variance.

\section{Items, Factors, and Scale Reliability}

EFA of Study 1 sample, generated a five-factor solution using 40 items that remained after dropping poorly performing items. Each of the remaining items clearly loaded onto one of the factors in a meaningful way, and all of the cross-loadings were low except for three items. These three items were retained because they loaded most heavily on the factor we expected, and cross-loaded in ways we expected on theoretical grounds. EFA in Study 2 found the same five factors and led us to discard three more items. Table 3 presents the final 37-item version of the AGPM with five factors that explain attitudes and Cronbach's alpha reliabilities for each factor. The five factors explained $60 \%$ of the total variance, which is excellent.

The confirmatory factor analysis in Study 2 found there was an acceptable fit between the model and the observed data: $\chi 2(607$, $n=317)=1686.486, P<.001, \mathrm{CFI}=.82$, RMSEA $=.07$, which supports the proposed five-factor structure.

The first factor includes seven items reflecting Embryo Concerns, such as "It bothers me that embryonic stem cell research destroys embryos." The second includes eight items tapping Privacy Concerns, such as "I have concerns about how my information will be kept private." The third factor includes nine items tapping Perceived Benefits, such as "Genetic testing would help me make decisions about my health." The fourth factor includes seven items tapping Nature Concerns, such as "I am concerned about making any changes to genes that will be passed on to future generations." The fifth factor includes 4 items tapping Social Justice Concerns, such as "I worry that people who have the least resources will not benefit from precision medicine." The alphas range from .77 to .90 , which suggests high internal consistency for all five subscales. 
Table 1. Aggregated Studies 1 and 2 demographic data

\begin{tabular}{|c|c|c|c|}
\hline Gender & Frequency (\%) & & Frequency (\%) \\
\hline Male & $549(52.3)$ & $75,001-112,000$ & $187(17.8)$ \\
\hline Female & $499(47.6)$ & Greater than 112,000 & $63(6.0)$ \\
\hline Age & & Health status & \\
\hline $20-29$ & 331 (31.6) & Excellent & $183(17.4)$ \\
\hline $40-49$ & $146(13.9)$ & Good & $318(30.3)$ \\
\hline $50-59$ & $75(7.1)$ & Fair & $157(15.0)$ \\
\hline 60 or older & $53(5.1)$ & Poor & $22(2.1)$ \\
\hline Education & & Very Poor & $5(.5)$ \\
\hline Associate's Degree & $118(11.2)$ & Large Town & $143(13.6)$ \\
\hline Bachelor's Degree & $432(41.2)$ & Small Town or Rural Area & $169(16.1)$ \\
\hline Master's Degree & $117(11.2)$ & Religious affiliation ${ }^{\mathrm{b}}$ & \\
\hline Doctoral Degree & $16(1.5)$ & Christian/Protestant & $157(30.4)$ \\
\hline Other & $2(.2)$ & Catholic & $105(20.3)$ \\
\hline Employment Status & & Jewish & $8(1.5)$ \\
\hline Employed part-time & $129(12.3)$ & Moslem & $6(1.2)$ \\
\hline Employed full-time & $654(62.3)$ & Hindu & $6(1.2)$ \\
\hline Hispanic or Latino & $116(11.1)$ & Seldom & $120(23.3)$ \\
\hline Not Hispanic or Latino & $914(87.1)$ & Never & $257(49.8)$ \\
\hline Prefer not to answer & $19(1.8)$ & Importance of spirituality ${ }^{c}$ & \\
\hline Race $^{a}$ & & Not at all important & $163(31.5)$ \\
\hline American Indian or Alaska Native & $32(3.1)$ & A little important & $85(16.4)$ \\
\hline Asian & $68(6.5)$ & Somewhat important & $82(15.9)$ \\
\hline Black or African American & $137(13.1)$ & Important & $106(20.5)$ \\
\hline Native Hawaiian or Pacific Islander & $4(.4)$ & Very important & $80(15.5)$ \\
\hline White & $836(79.7)$ & Political affiliation ${ }^{c}$ & \\
\hline Prefer not to answer & $13(1.2)$ & Republican & $150(29.1)$ \\
\hline Income & & Democrat & $213(41.3)$ \\
\hline $0-23,000$ & $142(13.5)$ & Independent or Other & $153(29.7)$ \\
\hline $23,001-45,000$ & $292(27.8)$ & Lean democratic ${ }^{d}$ & $90(59.2)$ \\
\hline $45,001-75,000$ & $348(33.2)$ & Lean republican ${ }^{d}$ & $62(40.8)$ \\
\hline
\end{tabular}

$n=1049$ except where noted.

${ }^{a}$ Not mutually exclusive; participants selected all that apply (sum is more than $100 \%$ ).

${ }^{b} n=517$ (variable collected only in the Study 2 sample).

$c_{n}=516$ (one missing response).

$\mathrm{d}_{n}=152$ (asked only of "Independent or Other" respondents; one missing response). 
Table 2. Descriptive statistics

\begin{tabular}{lccccc}
\hline & N & MIN & MAX & MEAN & SD \\
\hline AGPM: Total score & 1049 & 1.00 & 6.35 & 3.64 & 0.81 \\
\hline AGPM: Social justice concerns & 1049 & 1.00 & 7.00 & 4.71 & 1.29 \\
\hline AGPM: Privacy concerns & 1049 & 1.00 & 7.00 & 4.87 & 1.30 \\
\hline AGPM: Nature concerns & 1049 & 1.00 & 7.00 & 3.77 & 1.21 \\
\hline AGPM: Embryo concerns & 1049 & 1.00 & 6.89 & 3.02 & 1.17 \\
\hline AGPM: Perceived benefits & 1049 & 1.67 & 7.00 & 5.42 & 0.90 \\
\hline STI: Fidelity & 1049 & 1.00 & 4.00 & 2.54 & 0.56 \\
\hline STI: Competency & 1049 & 1.00 & 4.00 & 2.96 & 0.54 \\
\hline STI: Trustworthiness & 1049 & 1.00 & 4.00 & 2.61 & 0.85 \\
\hline STI: Integrity & 1049 & 1.00 & 4.00 & 2.63 & 0.76 \\
\hline AGT: Favorable & 1049 & 1.00 & 5.00 & 4.21 & 0.66 \\
\hline AGT: Reserved & 1049 & 1.29 & 5.00 & 3.00 & 0.69 \\
\hline TIPI: Extraversion & 1049 & 1.00 & 7.00 & 3.54 & 1.76 \\
\hline TIPI: Agreeableness & 1049 & 1.00 & 7.00 & 5.39 & 1.31 \\
\hline TIPI: Conscientiousness & 1049 & 1.00 & 7.00 & 5.58 & 1.30 \\
\hline TIPI: Neuroticism & 1049 & 1.00 & 7.00 & 4.40 & 0.99 \\
\hline TIPI: Openness & 516 & 1.00 & 5.00 & 2.04 & 1.34 \\
\hline Health status & 1.00 & 5.00 & 2.72 & 1.48 \\
\hline Religious practice & 1.00 & 7.00 & 5.15 & 1.39 \\
\hline Importance of spirituality & 100 & 6.00 & 4.49 & 1.04 \\
\hline & 1049 & & & \\
\hline
\end{tabular}

Religious practice and spirituality were assessed only in Study 2. AGPM, attitudes toward genomics and precision medicine; AGT, attitudes toward genetic testing; STI, system trust index; TIPI, 10-item personality inventory.

To compute an overall index, called the "total score," we reverse scored the perceived benefit items and calculated the mean of all AGPM items so higher scores indicate a greater level of concern with precision medicine activities. The overall AGPM has excellent Cronbach's alpha reliability $(\alpha=.92)$.

\section{Association of the AGPM with Existing Measures}

Table 4 presents the association of AGPM scales with existing measures. As predicted, the AGPM total score is positively correlated with the AGT "reserved" subscale, which taps perceived risks of genetic testing $(r=.67, P<.01)$, and negatively correlated with its "favorable" subscale, which taps perceived benefits $(r=-.58$, $P<.01)$. The AGPM privacy concerns subscale is significantly correlated with the "Systems Trust Index" (STI) subscales $(r=-.39$ to $-.40, p s<.01)$. As expected, the AGPM perceived benefit score was correlated with conscientiousness $(r=.22, P<.01)$; perceived benefit was also associated with agreeableness $(r=.24, P<.01)$ and openness $(r=.17, P<.01)$.

\section{Association of AGPM with Demographic Variables}

We also explored correlations (shown in Table 4) of demographic variables with the AGPM scales and the total score. Gender, ruralnonrural location, employment status, and income demonstrated very weak to near zero correlations with the AGPM. Similarly, health status demonstrated very modest associations with privacy concerns and social justice concerns with better health associated with lower concerns. Race was modestly related to AGPM scales; non-white individuals reported greater embryo and nature concerns. Age and education had correlations similar in magnitude as race: older people and those with greater education had greater concerns.

The political affiliation and religion variables had the largest associations with AGPM. Being Republican or republican-leaning was associated with higher concerns overall $(r=-.22)$, with embryo concerns $(r=-.35)$ being the subscale with the strongest association. Reporting affiliation with a religion, greater religious practice, and higher spirituality were related to higher AGPM total scores $(r=.21-.29)$, with moderate to large correlations with nature concerns $(r=.21-.24)$ and embryo concerns $(r=.39-.48)$.

\section{Discussion}

A total of 1049 adults in the USA completed the AGPM. The AGPM demonstrated excellent alpha reliability and validity through the expected correlations with existing validated measures of attitudes toward genetic testing and health information. The AGPM provides a total score that reflects overall level of concern with six genomic and precision medicine activities. It also has five underlying attitude subscales: perceived benefits, and concerns about embryos, privacy, nature, and social justice.

People in our sample moderately agreed with items that stated potential benefits of genomic and precision medicine activities $(\mathrm{M}=5.42$ on a 7-point bi-polar scale with 4 being neutral, $\mathrm{SD}=.90)$. Participants were more divided on concerns as indicated by larger standard deviations on the four concern scales.

Consistent with past studies, we found that regular practice of one's religion was correlated with the AGPM total score [34]. In contrast to what we hypothesized based on earlier studies [4], we did not find an association of living in a rural versus nonrural area with AGPM scores. The association of race with the AGPM total score was modest; there was greater concern on some subscales for non-white participants, albeit these effects were small. Given past findings [8], future research will need to further examine racial and ethnic differences. The AGPM could help discern if in certain populations some aspects of genomics and precision medicine are more or less concerning than other aspects.

Thirty years ago, the National Human Genome Research Institute began funding research on ethical, legal, and social implications (ELSI) of genomics [36]. Today, 10 institutes and centers of the National Institutes of Health support the ELSI program (PAR20-254), and the National Center for the Advancement of Clinical and Translational Science recently began funding research on ELSI of translational science, including precision medicine (RFA-TR20-001). As the field of ELSI research matures, it focuses on an "ever-expanding number of issues" [36]. Validated measures like the AGPM that holistically look at the larger enterprise of genomics and precision medicine offer essential tools for studying public attitudes.

The AGPM is based on the rationale that attitudes toward different activities are inter-related, just as the perception of the risks and benefits of activities are inter-related. This was born out in the current study: The perception of the benefits of genomic and precision medicine activities was significantly negatively associated with concerns about nature, embryos, and privacy. Thus, perceptions of the benefits of an activity such as genetic testing for Alzheimer's Disease might be affected by concerns about the larger enterprise of precision medicine involving activities that tamper with nature, harm embryos, or violate privacy. This is consistent with "moral foundations theory" which - in studies of $>24,000$ 
Table 3. Results from exploratory factor analysis for 37-item AGPM (Study 2)

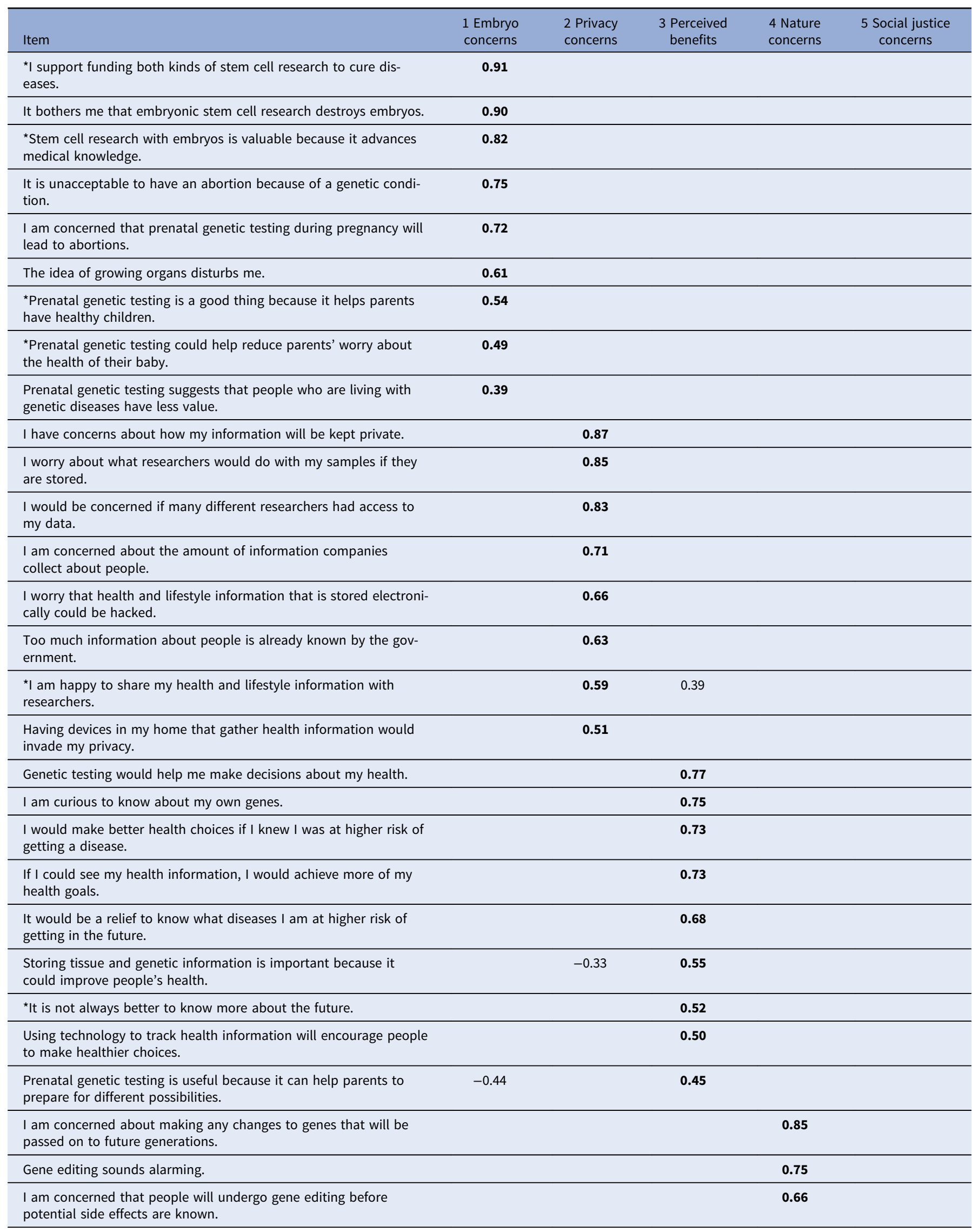


Table 3. (Continued)

\begin{tabular}{|c|c|c|c|c|c|}
\hline Item & $\begin{array}{l}1 \text { Embryo } \\
\text { concerns }\end{array}$ & $\begin{array}{l}2 \text { Privacy } \\
\text { concerns }\end{array}$ & $\begin{array}{l}3 \text { Perceived } \\
\text { benefits }\end{array}$ & $\begin{array}{l}4 \text { Nature } \\
\text { concerns }\end{array}$ & $\begin{array}{l}5 \text { Social justice } \\
\text { concerns }\end{array}$ \\
\hline I think gene editing is wrong because it is like playing God. & 0.38 & & & 0.60 & \\
\hline $\begin{array}{l}\text { I worry that gene editing will be used to change traits that are not } \\
\text { health related like eye color. }\end{array}$ & & & & 0.60 & \\
\hline${ }^{\star}$ Eliminating genetic diseases for future generations is a good idea. & & & 0.36 & 0.52 & \\
\hline *Gene editing seems exciting because it could fix certain diseases. & & & 0.36 & 0.36 & \\
\hline Genetic testing could make it hard to get insurance. & & & & & 0.80 \\
\hline Genetic tests could cause people to be treated unfairly. & & & & & 0.76 \\
\hline $\begin{array}{l}\text { Employers might use the results of genetic testing to hire only cer- } \\
\text { tain people. }\end{array}$ & & & & & 0.75 \\
\hline $\begin{array}{l}\text { I worry that people who have the least resources will not benefit } \\
\text { from precision medicine. }\end{array}$ & & & & & 0.31 \\
\hline$\%$ of variance explained & 27.84 & 11.92 & 8.69 & 6.76 & 4.80 \\
\hline \# items & 9 & 8 & 9 & 7 & 4 \\
\hline Cronbach's alpha & 0.89 & 0.90 & 0.86 & 0.85 & 0.77 \\
\hline
\end{tabular}

$n=200$. Loadings less than .30 are omitted. AGPM, attitudes toward genomics and precision medicine.

*Indicates reverse scored items on the primary factor; factor loading shown as the absolute value.

individuals across cultures - has found that moral intuitions about matters such as purity and sanctity serve to "unite ideological positions across a variety of issues" [37]. It is also consistent with a meta-analysis of attitudes toward embryonic stem cell research: views toward science were more strongly associated with views toward embryonic stem cell research than with political partisanship [38]. It is important to examine how views toward controversial components of precision medicine, including precision public health, might affect commitment to the overall enterprise.

Sometimes concerns about biomedical policies and practices can be addressed through education - e.g., when concerns rest upon so-called "myths" or misunderstanding of the facts. At other times, concerns rest upon differences in values, worldviews, or the interpretations of risks. In such cases, education may be of limited value. Rather, the situation may call for robust stakeholder engagement and negotiation of policies that satisfy concerns [39]. Our data suggest that the latter approach may be needed. Higher levels of education were associated with higher levels of concern with genomic and precision medicine activities. We do not think this is an anomaly of our sample. In a review of US public support for embryonic stem cell research from 2002-2010, Nisbet and Markowitz concluded that better educated members of the public held more reservations about the impact of science on society [34]. These findings about the relationship of education to concerns, combined with the influence of religion, may suggest that concerns with genomic and precision medicine activities are due to core values and worldviews rather than knowledge of the activities. Thus, concerns may be difficult to resolve through education alone.

Awareness of the role of underlying values on attitudes toward genomics and precision medicine may help researchers and practitioners identify issues worthy of discussion when presenting information about precision medicine activities. This might reduce barriers to engagement with precision medicine among those with more negative attitudes. However, engaging in such discussion may be challenging in the current polarized environment of the USA. A recent study indicates that the polarization of views on social and political issues contributes to rising rates of self-censorship: $40 \%$ said they do not feel free to speak their mind [40]. Interestingly, across the ideological spectrum, people with higher levels of education were more likely to self-censor. Tools such as the AGPM may help to elicit hidden views in settings where it is important to understand the concerns driving willingness to engage with precision medicine activities.

A strength of the AGPM is its accessibility to the general public. Data suggest that 1 in 5 adults in the USA has low literacy [41]. The AGPM was written at an 8th grade level, which was challenging given the complexity of the topic. To increase further comprehension of the text and issues, the AGPM uses embedded videos that describe each activity. This is extremely important as ELSI research seeks to move beyond the predominantly white, wealthy, and welleducated early engagers with genomics to more diverse, medically underserved populations who also tend to have lower literacy [42].

\section{Limitations and Future Directions}

While the samples reported in this paper were relatively large, they did not include sufficiently large numbers of participants in subgroups of interest to ELSI researchers to enable sophisticated analysis of the interaction between demographic variables. For example, while we had fairly large racial subgroups (137 who identified as Black, 116 who identified as Hispanic, and 68 who identified as Asian), these groups were not large enough to examine the interaction between race and religion. Similarly, while we had 169 participants who lived in small towns or rural areas, the sample was not large enough to identify geographic differences, much less explore whether such might be due to geographic differences per se or differences of religion or political orientation. Future research is needed to explore how the AGPM performs in ELSI projects with larger groups of interest. Future research is needed to explore how the AGPM performs in ELSI projects with larger groups of interest.

The AGPM currently takes a relatively long time to administer because it addresses a wide array of activities and latent factors, and activities are described in brief videos. In a brief follow up study 
Table 4. Correlations with AGPM

\begin{tabular}{|c|c|c|c|c|c|c|}
\hline & 1 & 2 & 3 & 4 & 5 & 6 \\
\hline 1. AGPM: Total score & 1 & & & & & \\
\hline 2. AGPM: Embryo concerns & $.72^{\star \star}$ & 1 & & & & \\
\hline 3. AGPM: Privacy concerns & $.72^{\star \star}$ & $.24^{\star \star}$ & 1 & & & \\
\hline 4. AGPM: Perceived benefits & $-.66^{\star \star}$ & $-.39^{\star \star}$ & $-.28^{\star \star}$ & 1 & & \\
\hline 5. AGPM: Nature concerns & $.81^{\star \star}$ & $.58^{\star \star}$ & $.48^{\star \star}$ & $-.40^{\star \star}$ & 1 & \\
\hline 6. AGPM: Social justice concerns & $.50^{\star \star}$ & $.08^{\star \star}$ & $.47^{\star \star}$ & $-.21^{\star \star}$ & $.27^{\star \star}$ & 1 \\
\hline 7. AGT: Favorable & $-.58^{\star \star}$ & $-.55^{\star \star}$ & $-.19^{\star \star}$ & $.68^{\star \star}$ & $-.47^{\star \star}$ & -.04 \\
\hline 8. AGT: Reserved & $.67^{\star \star}$ & $.43^{\star \star}$ & $.51^{\star \star}$ & $-.41^{\star \star}$ & $.49^{\star \star}$ & $.52^{\star \star}$ \\
\hline 9. STI: Fidelity & $-.39^{\star \star}$ & $-.17^{\star \star}$ & $-.40^{\star \star}$ & $.25^{\star \star}$ & $-.26^{\star \star}$ & $-.31^{\star \star}$ \\
\hline 10. STI: Competency & $-.49^{\star \star}$ & $-.30^{\star \star}$ & $-.40^{\star \star}$ & $.40^{\star \star}$ & $-.32^{\star \star}$ & $-.27^{\star \star}$ \\
\hline 11. STI: Trustworthiness & $-.40^{\star \star}$ & $-.12^{\star \star}$ & $-.40^{\star \star}$ & $.37^{\star \star}$ & $-.25^{\star \star}$ & $-.31^{\star \star}$ \\
\hline 12. STI: Integrity & $-.43^{\star \star}$ & $-.16^{\star \star}$ & $-.39^{\star \star}$ & $.35^{\star \star}$ & $-.30^{\star \star}$ & $-.32^{\star \star}$ \\
\hline 13. TIPI: Extraversion & -.02 & $.08^{\star}$ & -.03 & .04 & -.01 & $-.11^{\star \star}$ \\
\hline 14. TIPI: Agreeableness & $-.23^{\star \star}$ & $-.12^{\star \star}$ & $-.16^{\star \star}$ & $.24^{\star \star}$ & $-.13^{\star \star}$ & $-.17^{\star \star}$ \\
\hline 15. TIPI: Conscientiousness & $-.21^{\star \star}$ & $-.15^{\star \star}$ & $-.11^{\star \star}$ & $.22^{\star \star}$ & $-.11^{\star \star}$ & $-.19^{\star \star}$ \\
\hline 16. TIPI: Neuroticism & -.02 & $-.07^{\star}$ & -.01 & .04 & .04 & .01 \\
\hline 17. TIPI: Openness & $-.20^{\star \star}$ & $-.23^{\star \star}$ & -.02 & $.17^{\star \star}$ & $-.16^{\star \star}$ & $-.07^{\star}$ \\
\hline 18. Health status & -.05 & .03 & $-.08^{\star \star}$ & .05 & -.03 & $-.12^{\star \star}$ \\
\hline 19. Religious affiliation $(n=517)$ & $.21^{\star \star}$ & $.39^{\star \star}$ & .02 & -.06 & $.21^{\star \star}$ & $-.12^{\star \star}$ \\
\hline 20. Religious practice $(n=516)$ & $.29^{\star \star}$ & $.48^{\star \star}$ & .07 & -.08 & $.22^{\star \star}$ & -.08 \\
\hline 21. Spirituality $(n=516)$ & $.26^{\star \star}$ & $.44^{\star}$ & $.09^{\star}$ & -.04 & $.24^{\star \star}$ & $-.09^{\star}$ \\
\hline 22. Age & $.13^{\star \star}$ & .05 & $.11^{\star \star}$ & $-.10^{\star \star}$ & $.08^{\star \star}$ & $.16^{\star \star}$ \\
\hline 23. Gender $(n=1048)$ & .00 & -.01 & .03 & -.02 & $-.08^{\star}$ & .05 \\
\hline 24. Race $(n=1036)$ & $-.08^{\star}$ & $-.11^{\star \star}$ & -.05 & $-.06^{\star}$ & $-.13^{\star \star}$ & -.01 \\
\hline 25. Location & .01 & -.01 & .04 & .02 & .02 & -.01 \\
\hline 26. Education & $.12^{\star \star}$ & .06 & $.09^{\star \star}$ & $-.07^{\star}$ & .06 & $.13^{\star \star}$ \\
\hline 27. Employment status & -.02 & .01 & .00 & .02 & .00 & $-.11^{\star \star}$ \\
\hline 28. Income $(n=1032)$ & -.03 & .02 & -.05 & .05 & .02 & $-.08^{\star}$ \\
\hline 29. Political affiliation $(n=515)$ & $-.22^{\star \star}$ & $-.35^{\star \star}$ & $-.09^{\star}$ & $.12^{\star \star}$ & $-.13^{\star \star}$ & $.09^{\star}$ \\
\hline
\end{tabular}

$n=1049$, except where noted. Correlations are Pearson (continuous variables), Spearman (ordered categorical variables), and Point-biserial (dichotomous variables). Coding for dichotomous variables is as follows. Religious affiliation: no religion (0), religious affiliation (1). Gender: male (0), female (1). Race: non-white $(0, n=233)$, White (1, $n=803)$. For purposes of analysis, individuals reporting a racial identity other than, or in addition to, White were classified as non-white. Location: rural (0), non-rural (1). Employment status: other status (0), fulltime (1). Political affiliation:

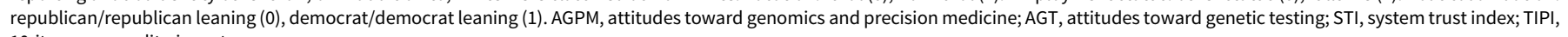
10 -item personality inventory.

${ }^{\star} P<.05,{ }^{\star \star} P<.01$.

(see Appendix), we piloted a text-only version of the AGPM and determined that mean scores and standard deviations do not differ significantly, and it takes approximately $8 \mathrm{~min}$ less to administer (19.7 versus $11.5 \mathrm{~min}$ ). Future research is needed to determine how well the text only version works with lower literacy participants.

We will share the AGPM with ELSI researchers to enable them to explore factors that predict attitudes toward genomics and precision medicine, to determine the effects of these attitudes on health behaviors, and to examine the effects of interventions to shape attitudes. The AGPM may be requested at https:// bioethicsresearch.org/research-services/testing-services/.

Supplementary Material. To view supplementary material for this article, please visit https://doi.org/10.1017/cts.2021.774.
Acknowledgements. This project was supported by the Bander Professorship for Medical Ethics and Professionalism at Washington University School of Medicine, and grants from the National Center for Advancing Translational Sciences (UL1 TR002345) and the National Human Genome Research Institute (K01HG008990).

Disclosures. The authors have no conflicts of interest to declare.

\section{References}

1. Precision Medicine Initiative (PMI) Working Group. The Precision Medicine Initiative Cohort Program-Building a Research Foundation for 21st Century Medicine. Bethesda, MD: National Institutes of Health, 2015. 
2. Wagner JK, Peltz-Rauchman C, Rahm AK, Johnson CC. Precision engagement: the PMI's success will depend on more than genomes and big data. Genetics in Medicine 2016; 19(6): 620-624.

3. Sankar PL, Parker LS. The precision medicine initiative's all of us research program: an agenda for research on its ethical, legal, and social issues. Genetics in Medicine 2017; 19(7): 743-750.

4. Riesgraf RJ, Veach PM, MacFarlane IM, LeRoy BS. Perceptions and attitudes about genetic counseling among residents of a midwestern rural area. Journal of Genetic Counseling 2015; 24(4): 565-579.

5. National Institute of Health. Theory at a Glance: A Guide for Health Promotion Practice, 2nd ed. Bethesda MD: National Institute of Health, National Cancer Institute, 2005.

6. Gille F, Smith S, Mays N. Why public trust in health care systems matters and deserves greater research attention. Journal of Health Services Research \& Policy 2015; 20(1): 62-64.

7. Blendon RJ, Benson JM, Hero JO. Public trust in physicians-U.S. medicine in international perspective. New England Journal of Medicine 2014; 371(17): 1570-1572.

8. Suther S, Kiros GE. Barriers to the use of genetic testing: a study of racial and ethnic disparities. Genetics in Medicine 2009; 11(9): 655-662.

9. Morren M, Rijken M, Baanders AN, Bensing J. Perceived genetic knowledge, attitudes towards genetic testing, and the relationship between these among patients with a chronic disease. Patient Education and Counseling 2007; 65(2): 197-204.

10. Etchegary H, Cappelli M, Potter B, Vloet M, Graham I, Walker M, Wilson B. Attitude and knowledge about genetics and genetic testing. Public Health Genomics 2010; 13(2): 80-88.

11. Henneman L, Timmermans DR, Van Der Wal G. Public attitudes toward genetic testing: perceived benefits and objections. Genetic Testing 2006; 10(2): 139-145.

12. Cella D, Hughes C, Peterman A, et al. A brief assessment of concerns associated with genetic testing for cancer: the multidimensional impact of Cancer Risk Assessment (MICRA) Questionnaire. Health Psychology 2002; 21(6): 564-572.

13. Platt JE, Jacobson PD, Kardia SLR. Public trust in health information sharing: a measure of system trust. Health Services Research 2018; 53(2): 824-845.

14. Kaufman DJ, Baker R, Milner LC, Devaney S, Hudson KL. A survey of U.S adults' opinions about conduct of a Nationwide Precision Medicine Initiative(R) cohort study of genes and environment. PLoS One 2016; 11(8): e0160461.

15. Parikh RB, Schwartz JS, Navathe AS. Beyond genes and molecules - a precision delivery initiative for precision medicine. New England Journal of Medicine 2017; 376(17): 1609-1612.

16. Collins FS, Varmus H. A new initiative on precision medicine. New England Journal of Medicine 2015; 372(9): 793-795.

17. Jameson JL, Longo DL. Precision medicine-personalized, problematic, and promising. New England Journal of Medicine 2015; 372(23): 2229-2234.

18. Molster CM, Bowman FL, Bilkey GA, et al. The evolution of public health genomics: exploring its past, present, and future. Frontiers in Public Health 2018; 6: 247.

19. Jarvik GP, Amendola LM, Berg JS, et al. Return of genomic results to research participants: the floor, the ceiling, and the choices in between. American Journal of Human Genetics 2014; 94(6): 818-826.

20. Wolf SM, Burke W, Koenig BA. Mapping the ethics of translational genomics: situating return of results and navigating the research-clinical divide. The Journal of Law, Medicine \& Ethics 2015; 43(3): 486-501.

21. Medicine IO, Council NR. 2007 Amendments to the National Academies Guidelines for Human Embryonic Stem Cell Research. Washington, DC: The National Academies Press, 2007.
22. National Academies of Sciences, Engineering, and Medicine. Returning Individual Results to Participants: Guidance for a new Research Paradigm. Washington, DC: The National Academies Press, 2018.

23. National Academies of Sciences, Engineering Medicine. An Evidence Framework for Genetic Testing. Washington, DC: The National Academies Press, 2017.

24. Sankar PL, Cho MK. Engineering values into genetic engineering: a proposed analytic framework for scientific social responsibility. The American Journal of Bioethics 2015; 15(12): 18-24.

25. Henneman L, Bramsen I, Van Os TA, et al. Attitudes towards reproductive issues and carrier testing among adult patients and parents of children with cystic fibrosis (CF). Prenatal Diagnosis 2001; 21(1): 1-9.

26. Henneman L, Vermeulen E, van El CG, Claassen L, Timmermans DRM, Cornel MC. Public attitudes towards genetic testing revisited: comparing opinions between 2002 and 2010. European Journal of Human Genetics 2013; 21(8): 793-799.

27. Hietala M, Hakonen A, Aro AR, Niemelä P, Peltonen L, Aula P. Attitudes toward genetic testing among the general population and relatives of patients with a severe genetic disease: A survey from Finland. American Journal of Human Genetics 1995; 56: 1493-1500.

28. Clark LA, Watson D. Constructing validity: basic issues in objective scale development. Psychological Assessment 1995; 7(3): 309-319.

29. Willis G. Cognitive Interviewing: A Tool for Improving Questionnaire Design. Thousand Oaks, CA: Sage Publications, 2005.

30. Huff C, Tingley D. "Who Are These People?" Evaluating the demographic characteristics and political preferences of MTurk survey respondents. Research and Politics 2015; 2(3): 1-12.

31. Gosling SD, Rentfrow PJ, Swann WB. A very brief measure of the big-five personality domains. Journal of Research in Personality 2003; 37(6): 504-528.

32. Atherton OE, Robins RW, Rentfrow PJ, Lamb ME. Personality correlates of risky health outcomes: findings from a large internet study. Journal of Research in Personality 2014; 50: 56-60.

33. Hudson K, Scott J, Kalfoglou A. Public Awareness and Attitudes about Reproductive Technology. Baltimore, MD: Genetics and Public Policy Center, 2002.

34. Peters N, Rose A, Armstrong K. The association between race and attitudes about predictive genetic testing. Cancer Epidemiology, Biomarkers \& Prevention 2004; 13(3): 361-365.

35. Gallup. Gallup Historical Trends [Internet], 2018 [cited Aug 21, 2018]. (https://news.gallup.com)

36. McEwen JE, Boyer JT, Sun KY, Rothenberg KH, Lockhart NC, Guyer MS. The ethical, legal, and social implications program of the National Human Genome Research Institute: reflections on an ongoing experiment. Annual Review of Genomics and Human Genetics 2014; 15: 481-505.

37. Koleva SP, Graham J, Iyer R, Ditto PH, Haidt J. Tracing the threads: how five moral concerns (Especially Purity) help explain culture war attitudes. Journal of Research in Personality 2012; 46(2): 184-194.

38. Nisbet M, Markowitz EM. Understanding public opinion in debates over biomedical research: looking beyond political partisanship to focus on beliefs about science and society. PLoS One 2014; 9(2): e88473.

39. DuBois JM. The ethics of creating and responding to doubts about death criteria. The Journal of Medicine and Philosophy 2010; 35(3): 365-380.

40. Gibson JL, Sutherland JL. Keeping your mouth shut: spiraling self-censorship in the United States. 2020. Available at SSRN: https://ssrn.com/ abstract $=3647099$ or http://dx.doi.org/10.2139/ssrn.3647099.

41. U.S. Department of Education. Data Point: Adult Literacy in the United States. NCES 2019-179 ed. Washington DC: U.S. Department of Education, 2019.

42. Janssens AC. The hidden harm behind the return of results from personal genome services: a need for rigorous and responsible evaluation. Genetics in Medicine 2014; 17(8): 621-622. 